\title{
Variation in the C-Reactive Protein Gene Is Associated with Serum Levels of CRP in Patients with Acute Ischemic Stroke
}

\author{
Heleen M. den Hertog ${ }^{a}$ Evita G. van den Herik ${ }^{a}$ Diederik W.J. Dippel ${ }^{\mathrm{a}}$ \\ Peter J. Koudstaala ${ }^{\mathrm{a}}$ Moniek P.M. de Maat ${ }^{\mathrm{b}}$ \\ Departments of ${ }^{\mathrm{a}}$ Neurology and ${ }^{\mathrm{b}}$ Hematology, Erasmus MC University Medical Center, Rotterdam, The Netherlands
}

Key Words

CRP gene $\cdot$ CRP levels $\cdot$ Ischemic stroke $\cdot$ Acute phase

\begin{abstract}
Background and Purpose: Elevated levels of C-reactive protein (CRP) are found in up to three quarters of patients with acute ischemic stroke and are associated with poor outcome. We investigated whether haplotypes representing common variations in the CRP gene are associated with levels of CRP in patients with acute ischemic stroke. Methods: We included 185 patients with ischemic stroke in whom CRP was measured within $24 \mathrm{~h}$ of symptom onset. Common haplotypes within the CRP gene were determined by 3 genotype-tagging single-nucleotide polymorphisms (SNPs). Results: Four haplotypes with frequencies $>5 \%$ covered $99.2 \%$ of the genetic variation. Haplotype 4 (CCG, frequency $8.3 \%$ ) was associated with a $20.6 \mathrm{mg} / \mathrm{l}(95 \% \mathrm{Cl}, 9.8-30.4)$ stronger increase in CRP level as compared with haplotype 1 (CTC, frequency $33.7 \%)$. Conclusion: Variation in the CRP gene is associated with levels of CRP in acute ischemic stroke.
\end{abstract}

Copyright $\odot 2010$ S. Karger AG, Basel
(C) 2010 S. Karger AG, Basel

$1015-9770 / 10 / 0294-0372 \$ 26.00 / 0$

Fax +41613061234 E-Mail karger@karger.ch www.karger.com

\section{Background}

C-reactive protein (CRP) is a strong acute-phase reactant. Elevated levels of serum CRP are found in up to three quarters of patients with acute ischemic stroke and are associated with poor outcome [1-6]. This leads to interest in the use of CRP as a biomarker of prognosis of ischemic stroke. Moreover, CRP may contribute to secondary brain damage after focal cerebral ischemia, possibly via a complement-mediated exacerbation of tissue injury [7].

The CRP concentrations are under genetic influence. Family and twin studies found that additive genetic factors account for $27-40 \%$ of the variance in CRP, indicating a role of DNA sequence variation in determining serum protein levels [8]. Furthermore, there is accumulating evidence for an association between single nucleotide polymorphisms (SNPs) in the CRP gene and levels of CRP $[9,10]$.

This led us to hypothesize that levels of CRP in the acute phase of ischemic stroke are under genetic influence as well, and that haplotypes associated with higher CRP levels are associated with an increased risk of poor outcome after acute ischemic stroke.

Only limited and inconsistent data are available on the association between SNPs in the CRP gene and CRP concentrations in patients with acute ischemic stroke $[3,11]$.

Heleen M. den Hertog

Department of Neurology, Erasmus MC University Medical Center Rotterdam PO Box 2040

NL-3000 CA Rotterdam (The Netherlands)

Tel. +31 10704 0704, Fax +31 10704 4721, E-Mail m.denhertog@erasmusmc.nl 
In the present study, we investigated whether haplotypes representing common variations in the CRP gene are associated with levels of CRP in patients with acute ischemic stroke.

\section{Methods}

\section{Study Population}

Patients were derived from the Erasmus Stroke Study, a project aimed at collecting clinical information, blood samples and DNA of all patients with neurovascular diseases admitted to Erasmus University Medical Center.

For the present study, we evaluated all patients with ischemic stroke admitted between December 2005 and December 2008 in whom venous blood was collected within $24 \mathrm{~h}$ of symptom onset.

Written informed consent was obtained from all patients, signed by the participants or a first-degree relative, as approved by the Institutional Ethics Committee.

\section{Baseline Characteristics}

Baseline clinical information was extracted from the trial records. This included a quantification of stroke severity according to the National Institutes of Health Stroke Scale (NIHSS) [12], ischemic stroke subtype according to the TOAST classification [13], and cardiovascular risk factors.

\section{Measurement of CRP}

CRP levels were determined by means of the Roche Modular Assay. The range of measurement is $1-285 \mathrm{mg} / \mathrm{l}$ with a variation coefficient of $4.6 \%$.

\section{CRP Polymorphism Genotyping}

In the Seattle SNPs program for Genomic applications, 31 SNPs were identified in the CRP gene on chromosome 1q21 (http://www.pga.gs.washington.edu/data/crp, 'visual haplotype' option).

In 23 unrelated individuals of European descent, these SNPs formed 4 well-defined haplotypes with frequencies of more than $5 \%$. By selecting 3 tagging SNPs, the total common variation in the CRP gene is described. We selected the following tagging SNPs: 1184 C > T (rs1130864), 2042 C > T (rs1205) and 2911 C > $\mathrm{G}(\mathrm{rs} 3093068)$

DNA was extracted according to standard procedures and stored at $-20^{\circ} \mathrm{C}$. Genotypes were determined in genomic DNA of $2 \mathrm{ng}$ with the Taqman allelic discrimination assay (Applied Biosystems, Foster City, Calif., USA) and end-point readings of fluorescence were performed on Taqman Prism 7900HT (Applied Biosystems).

\section{Statistical Analysis}

SNPs were tested for Hardy-Weinberg equilibrium with a $\chi^{2}$ test. The association between CRP haplotypes and levels of CRP were assessed with the non-parametric haplo.score function of Haplo Stats (http://cran-r.project.org/scr/contrib/Descriptions/ haplostats). We adjusted for age, sex and stroke severity on admission by means of multiple linear regression.

Variation in the C-Reactive Protein Gene and CRP Levels in Acute Ischemic Stroke
Table 1. Clinical characteristics of the patients $(n=185)$

\section{Demographics}

Age, years

$64 \pm 15$

Sex, male, n (\%) $98(53)$

Cardiovascular risk factors

Hypertension, $\mathrm{n}(\%)$

$98(53)$

Atrial fibrillation, $\mathrm{n}(\%)$

Diabetes mellitus, $\mathrm{n}(\%)$

$29(16)$

Current cigarette smoking, $\mathrm{n}(\%)$

Hypercholesterolemia, n (\%) $85(46)$

\section{Medical history}

Previous stroke, $\mathrm{n}(\%)$

Previous myocardial infarction, $\mathrm{n}(\%) \quad 31$ (17)

Peripheral vascular disease, $\mathrm{n}(\%)$

\section{Stroke subtype*}

Large vessel disease, $\geq 50 \%$ stenosis, n (\%) 28 (15)

Cardiac source of embolism, n (\%) 30 (16)

Small vessel occlusion, $\mathrm{n}(\%) \quad 27(15)$

Other determined etiology, n (\%) 21 (11)

Undetermined/negative evaluation, n (\%) 79 (43)

Stroke severity

Median (range) NIHSS score $\$$ 4(0-22)

Physical examination

Systolic blood pressure on admission

$167 \pm 34$

Diastolic blood pressure on admission

$86 \pm 20$

Laboratory assessments

Median (IQR) time from stroke onset to measurement of CRP, h (range) $6.6(3-13.9)$

Treatment

Treatment with rt-PA, n (\%)

* Based on the Trial of ORG 10172 in Acute Stroke Therapy (TOAST) criteria [13].

$\$$ Scores on the National Institutes of Health Stroke Scale (NIHSS) [12].

\section{Results}

Between December 2005 and December 2008, 561 patients with ischemic stroke were included in the Erasmus Stroke Study. Of these patients, 376 were excluded for the present study because of CRP measurement was not accomplished within $24 \mathrm{~h}$ of stroke onset $(\mathrm{n}=140)$, DNA was not available (226) or genotyping failed for 2 or 3 out of 3 SNPs $(n=10)$.

In the total study population, the mean age was 64 (SD 15), 53\% were male and the median NIHSS score was 4 (range 0-22) (table 1). Mean CRP level was $10 \mathrm{mg} / \mathrm{l}$ (SD 27). Median time from onset of symptoms to CRP measurement was approximately $7 \mathrm{~h}$. 


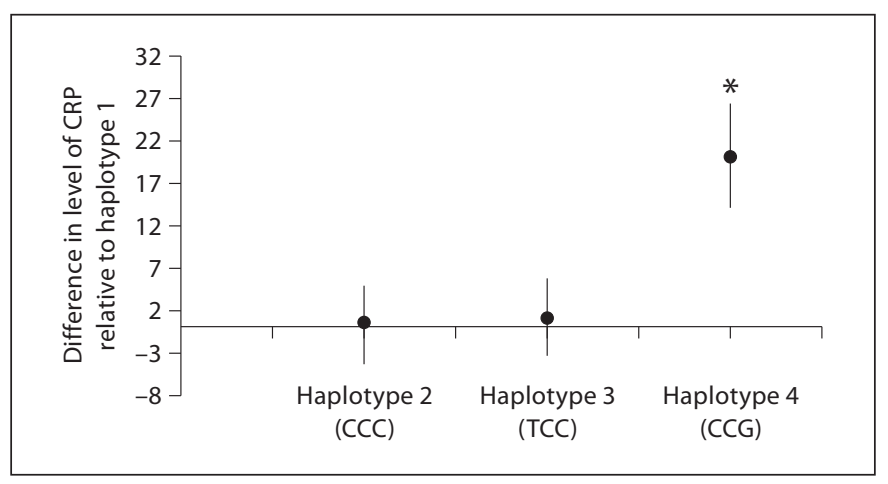

Fig. 1. Relative effects of CRP gene haplotypes on levels of CRP $(\mathrm{mg} / \mathrm{l}) .{ }^{*} \mathrm{p}<0.01$. Regression coefficients were adjusted for age, sex and NIHSS score on admission. Coefficients reflect the mean difference in levels of CRP relative to haplotype 1 (CTC).

All SNPs were in Hardy-Weinberg equilibrium. The $1,184 \mathrm{~T}$-allele was present in $25.9 \%$, the $2,042 \mathrm{~T}$-allele was present in $34.5 \%$ and the $2911 \mathrm{G}$-allele in $8.6 \%$ of 370 chromosomes.

Four common haplotypes were identified (table 2). The remaining haplotypes (CTG, TCG, TTC) were present in less than $5 \%$.

Haplotype 4 (CCG) was associated with a significant stronger increase in CRP level $(20.6 \mathrm{mg} / \mathrm{l}$; 95\% CI, 9.830.4) relative to the reference haplotype 1 (CTC) (table 2 and fig. 1). Adjustment for age, sex and NIHSS score did not attenuate this association (fig. 1).

\section{Discussion}

In this study, we found that SNPs in the CRP gene were associated with levels of CRP within $24 \mathrm{~h}$ of ischemic stroke onset. Haplotype 4 (CCG) was associated with significant higher levels of CRP than haplotype 1 (CTC).

Our results provide further proof that, apart from environmental factors, genetic variations may influence levels of CRP. Several studies found an association between CRP haplotypes and levels of CRP in diseases in which inflammation is involved $[9,14,15]$. The direction of the haplotype-CRP level associations are also supported by previous studies that have used the same polymorphisms to reconstruct the haplotypes $[9,14,15]$. Two previous studies that investigated the association between SNPs in the CRP gene and levels of CRP in patients with acute ischemic stroke cannot be compared directly with ours, because only single SNPs were studied $[3,11]$.
Table 2. Frequency of haplotypes and association between CRP haplotypes and levels of CRP

\begin{tabular}{lccc}
\hline Haplotype & Haplotype frequency, \% & Haplo score & p value* \\
\hline 1 (CTC) & 33.7 & -0.75 & 0.45 \\
2 (CCC) & 31.7 & -0.01 & 0.98 \\
3 (TCC) & 25.5 & 0.41 & 0.68 \\
4 (CCG) & 8.3 & 4.49 & $<0.01$ \\
\hline
\end{tabular}

* p values were obtained using haplo score, after 2,377 simulations. The frequencies refer to the reference (Seattle) population.

The present study has some limitations. First, the study compromised a small number of patients. As a result, the precision of our estimates is limited. Furthermore, because of this small number of patients we could not adjust the association between CRP haplotypes and levels of CRP for vascular risk factors, like diabetes mellitus and smoking, which might have influenced the levels of CRP. Second, our results did not include information about ethnicity. Allele frequencies have been reported to differ between ethnic groups. However, the haplotype structures are similar and therefore the direction and size of changes in CRP levels associated with most SNPs might be similar regardless of ethnic group [15].

A third issue that warrants consideration in this study is that DNA was lacking for 226 patients who were admitted within $24 \mathrm{~h}$ of symptom onset. On the other hand, comparison of the excluded patients with the study population showed no significant differences with regard to baseline characteristics or case fatality. Hence, it is not likely that it has substantially influenced the results.

Finally, our study focused on CRP levels within $24 \mathrm{~h}$ of stroke onset. As CRP may peak several days after ischemic stroke, CRP measured at later time points than in our study may better reflect the magnitude of the inflammatory reaction. Furthermore, we did not have levels of CRP prior to ischemic stroke or several months after the stroke. It would be interesting to compare the association between CRP haplotypes and these levels with that of stroke-free participants. On the other hand, a previous study did not find an association between CRP genotypes and baseline levels of CRP nor between CRP genotypes and levels of CRP in stroke-free participants [10].

Increases in CRP levels following ischemic stroke may reflect a systemic inflammatory response, the extent of tissue injury, or concurrent infections. Interestingly, in animal models of focal cerebral ischemia, CRP increased 
secondary brain damage through activation of the complement system $[7,16]$. These findings suggest that understanding genotype-phenotype associations of CRP polymorphisms may provide a genetic basis for the future development of tailored therapeutic strategies in ischemic stroke.
In conclusion, variation in the CRP gene is associated with levels of CRP in acute ischemic stroke. Further studies are needed to investigate the relation between variation in the CRP gene, levels of CRP and clinical outcome after acute ischemic stroke.

\section{References}

1 Di NM, Schwaninger M, Cappelli R, et al: Evaluation of C-reactive protein measurement for assessing the risk and prognosis in ischemic stroke: a statement for health care professionals from the CRP Pooling Project members. Stroke 2005;36:1316-1329.

-2 Masotti L, Ceccarelli E, Forconi S, Cappelli $\mathrm{R}$ : Prognostic role of $\mathrm{C}$-reactive protein in very old patients with acute ischaemic stroke. J Intern Med 2005;258:145-152.

-3 Montaner J, Fernandez-Cadenas I, Molina CA, et al: Poststroke C-reactive protein is a powerful prognostic tool among candidates for thrombolysis. Stroke 2006;37:12051210 .

4 den Hertog HM, van Rossum JA, van der Worp HB, van Gemert HMA, de Jonge R, Koudstaal PJ, Dippel DWJ, PAIS Investigators: C-reactive protein in the very early phase of acute ischemic stroke: association with poor outcome and death. J Neurol 2009, Epub.

5 Song IU, Kim JS, Kim YI, Lee KS, Jeong DS, Chung SW: Relationship between high-sensitivity C-reactive protein and clinical functional outcome after acute ischemic stroke in a Korean population. Cerebrovasc Dis 2009; 28:545-550.
6 Welsh P, Barber M, Langhorne P, Rumley A, Lowe GD, Stott DJ: Associations of inflammatory and haemostatic biomarkers with poor outcome in acute ischaemic stroke. Cerebrovasc Dis 2009;27:247-253.

7 Gill R, Kemp JA, Sabin C, Pepys MB: Human C-reactive protein increases cerebral infarct size after middle cerebral artery occlusion in adult rats. J Cereb Blood Flow Metab 2004; 24:1214-1218.

8 Pankow JS, Folsom AR, Cushman M, et al: Familial and genetic determinants of systemic markers of inflammation: the NHLBI family heart study. Atherosclerosis 2001;154: 681-689.

-9 Kardys I, de Maat MP, Uitterlinden AG, Hofman A, Witteman JC: C-reactive protein gene haplotypes and risk of coronary heart disease: the Rotterdam Study. Eur Heart J 2006;27:1331-1337.

10 Arenillas JF, Massot A, Varez-Sabin J, et al: C-reactive protein gene C1444T polymorphism and risk of recurrent ischemic events in patients with symptomatic intracranial atherostenoses. Cerebrovasc Dis 2009;28: 95-102.
11 Ben-Assayag E, Shenhar-Tsarfaty S, Bova I, et al: Triggered C-reactive protein (CRP) concentrations and the CRP gene $-717 \mathrm{~A}>\mathrm{G}$ polymorphism in acute stroke or transient ischemic attack. Eur J Neurol 2007;14:315320.

12 Brott T, Adams HP Jr, Olinger CP, et al: Measurements of acute cerebral infarction: a clinical examination scale. Stroke 1989;20: 864-870.

13 Adams HP, Bendixen BH, Kappelle LJ, et al: Classification of subtype of acute ischemic stroke: definitions for use in a multicenter clinical trial. TOAST. Trial of Org 10172 in Acute Stroke Treatment. Stroke 1993;24:35-

14 Miller DT, Zee RY, Suk DJ, et al: Association of common CRP gene variants with CRP levels and cardiovascular events. Ann Hum Genet 2005;69:623-638.

15 Teng MS, Hsu LA, Wu S, Chang HH, Chou $\mathrm{HH}, \mathrm{Ko}$ YL: Association between C-reactive protein gene haplotypes and C-reactive protein levels in Taiwanese: interaction with obesity. Atherosclerosis 2009;204:e64-e69

16 Griselli M, Herbert J, Hutchinson WL, et al: $\mathrm{C}$-reactive protein and complement are important mediators of tissue damage in acute myocardial infarction. J Exp Med 1999;190: $1733-1740$. 